\title{
Communicating Movement Control Order during Covid-19: A Framing Analysis of News Portal and Instagram
}

\author{
Wan Norshira Wan Mohd Ghazali1*iD, Noor Dzuhaidah Osman² iD, \\ Syahirah Abdul Shukor ${ }^{3}$ (D)
}

${ }^{1}$ Department of Communication, Kulliyyah of Islamic Revealed Knowledge and Human Sciences, International Islamic University Malaysia (IIUM), Malaysia.

Email: wannorshira@iium.edu.my

${ }^{2}$ Faculty of Syariah and Law, Universiti Sains Islam Malaysia (USIM), Malaysia.

Email: noordzuhaidah@usim.edu.my

${ }^{3}$ Faculty of Syariah and Law, Universiti Sains Islam Malaysia (USIM), Malaysia.

Email: syahirah@usim.edu.my

\section{CORRESPONDING}

AUTHOR (*):

Wan Norshira Wan Mohd

Ghazali

(wannorshira@iium.edu.my)

KEYWORDS:

Interactive features

Instagram

Framing

Social media presence

News portal

\section{CITATION:}

Wan Norshira Wan Mohd Ghazali, Noor Dzuhaidah Osman \&

Syahirah Abdul Shukor. (2022).

Communicating Movement Control Order during Covid-19: A Framing Analysis of

News Portal and Instagram. Malaysian Journal of Social Sciences and Humanities (MJSSH), 7(2), e001275.

https://doi.org/10.47405/mjssh.v7i2.1275

\begin{abstract}
Movement Control Order (MCO) was implemented in Malaysia on March 18, 2020, to contain the spread of Covid19. The mass media has played a great role in communicating the new restrictions and orders that regulated many public activities. All relevant channels including social media were employed by the mass media to ensure everyone was aware of the new norms. This study chooses Berita Harian, a Malay language newspaper, and examines its news portal and Instagram posts to explore the communication of standard operating procedure (SOPs) messages related to MCO as issued by the National Security Council (NSC) of Malaysia. Quantitative content analysis was used to explore the portrayal of SOPs using message styles and interactive elements. Initial results revealed that Berita Harian's news portal still placed great importance on the text and non-narrative elements accompanied by photos to educate and influence the public about the rules related to SOPs. While on Instagram, videos were used dominantly that are visually more attractive, engaging, and narrative in nature. The study argued that the discussion of framing can be extended by emphasising interactive elements as the aspects of coverage that can contribute to the way an issue is framed. In conclusion, Instagram should be regarded as an important platform for media to reach out to more incidental users in communication messages related to Covid-19 MCO.
\end{abstract}

Contribution/Originality: This study contributes to extending the framing concept by emphasising the adoption of interactive elements as the aspects of coverage. Through these elements, framing will go beyond highlighting certain parts of an issue or content presentation to make information more visible and significant to the audience. 


\section{Introduction}

When the Movement Control Order (MCO) was introduced by the Malaysian government on March 18, 2020, the communication of SOPs messages has since become the media's core business. With the power to shape, construct, and alter the minds of the public (Jamal \& Ganapathy, 2021), the media has been used to make people aware of the new restrictions. The measure was taken by the government based on the advice of the World Health Organization (WHO) to curb the spread of the Covid-19 virus. Covid-19 was first reported in December 2019 and originated from Wuhan, China. As Covid-19 cases continued to surge in Malaysia, the mainstream media have been steadfast to communicate messages from Malaysian National Security Council (NSC) in coordinating the implementation of MCO.

Covid-19 has since become an actively searched topic on the Internet. The topics searched range from infection statistics and recovery, pandemic affected areas, relevant SOPs to be complied with, health measures, legal requirements to other related matters. Badawy et al. (2020) mentioned that Malaysia was able to contain the pandemic on the national level due to citizen awareness. The official data released by the Malaysian national news agency, Bernama, helped the public to be aware of the SOPs that are in place. Tahir et al. (2020) highlighted that it is important to use visual communication in communicating SOPs. Undeniably, visual communication has become a widely used method in producing messages of Covid-19 SOPs on mass media. As there are 27.3 million Malaysians registered as members of social media (Nurhayati-Wolff, 2020), the use of visual communication has been the demand to correspond with the social media features and thus giving more choices for people to obtain Covid-19 information.

Social media has long changed the common practice of journalism in Malaysia. Bowd (2016) indicated that social media "create and expand audiences, increase geographical reach, respond more quickly than ever before to news events and issues, and interact with news consumers in more immediate and direct ways" (p. 130). As a communication tool, the public reliance on social media can be observed in the way information is searched and obtained. As the use of social media enlist vast opportunities, however, the traditionally performed functions by traditional news are slowly fading. The situation forced the traditional media to respond innovatively. Currently, besides having to package and distribute news on online portals, news organisations have maintained a presence on social media to reach more audience and increase engagement.

Therefore, it is the focus of this study to examine how Berita Harian used its news portal and Instagram in communicating Covid-19 standard operating procedures' (SOPs) messages related to movement orders as issued by the Malaysian National Security Council (NSC). As most news organisations have incorporated social media as a mode of communication, the study aims to explore the function of Instagram in disseminating information besides the content in the news portal. Through the lens of framing, this paper aims to identify if interactive features enhance the portrayal of Covid-19's SOPs.

\section{Literature Review}

\subsection{Berita Harian Newspaper and Instagram}

Berita Harian is an important avenue to contribute significantly and dynamically to target readerships by focusing on issues of public concerns (Ghazali et al., 2020). Berita 
Harian is considered the leading Malay newspaper in Malaysia and is owned by The New Straits Times Press (NSTP). According to Zulkafli et al. (2014), among the Malay mainstream daily newspapers, over half of the subjects $(60.78 \%)$ preferred Berita Harian. The Malay newspaper further incorporates different platforms of social media to draw more audience. Both are considered vital tools of communication in the current news environment. As observed, the adoption of social media by the mainstream media in Malaysia along with online news portal is common. For example, Berita Harian's news portal and Instagram are imperative in framing current issues as both support interactive elements. Although Instagram is highly visual as opposed to the news portal, the analysis can inform by what means visual interactivity helps to convey information related to SOPs. Previous research showed that the image-based Instagram played a great role to communicate the Zika virus during its outbreak in 2016 (Ngai et al., 2020). A more recent study further explored how government officials in Indonesia used Twitter in handling Covid-19 (Machmud et al., 2021). In this study, Berita Harian's news portal and Instagram were selected as the samples because research aims to explore the use of different platforms from the same news organisation in the coverage of Covid-19 SOPs. The exploratory research on Berita Harian online newspaper and Instagram could indicate the extent the interactive features are used in the coverage of Covid-19 SOPs.

\subsection{Framing}

It is no doubt that the fast-changing landscape of technology has accelerated the shift undertaken by media to present news (Barnard, 2016; Usher, 2014; Pavlik, 2000). One of the ways to package news is through framing. Framing, an extension of the agendasetting theory, was first introduced by Goffman (1974) and amended by Entman (1993). Bryant and Miron (2004) contended that framing is a well-known and widely applied methodology in communication studies and has positioned itself in communication science. Much research on politics, health, economics, crime and others had employed framing as a framework.

The process of framing begins with the selection of "some aspects of perceived reality [to] make them more salient in a communicating text, in such a way as to promote a particular problem definition, causal interpretation, and moral evaluation, and/or treatment recommendation for the item described" (Entman, 1993, p. 52). In communication, a frame refers to the media frame that conveys messages and information in the form of words, images, phrases, videos, and others. Matthes (2009) stated that "frame analysis examines the selection and salience of certain aspects of an issue by exploring images, stereotypes, metaphors, actors, and messages" (p. 1). These aspects of issues can contribute to the way an event is framed. Wojdynski (2008) suggested that the role of these aspects (e.g., visual content and photos) is to accompany the news portrayal of an event thus affecting how people perceive it.

Based on these discussions, this study proposes that message styles and interactive elements play an equally important role as the content to make an issue more salient to the public, especially on the media presentation of Covid-19 SOPs. Earlier studies on framing mostly discussed the way news are portrayed through different types of frames. To the knowledge of the researchers', limited studies have looked further into interactive elements that could be adopted as part of news framing. As news organisations are now operating both online and offline (Stroud et al., 2016), it is important to analyse how these elements are adopted and used on different platforms (website and social media). While the role of social media as sources for breaking news 
of major events is recognised (Rich, 2014), little evidence is found on the use of social media by the mainstream media organisations in extending the packaging and distribution of news. This study argues that the social media presence of the Malaysian news organisation, particularly Berita Harian, is worth to be researched. Therefore, the present study addresses three main research questions:

i. How much do Berita Harian online portal and Instagram cover about Covid-19 SOPs?

ii. What is the message style used by Berita Harian online portal and Instagram in covering Covid-19 SOPs?

iii. How did Berita Harian online portal and Instagram use interactive features on the coverage of Covid-19 SOPs?

\section{Methodology}

\subsection{Content analysis}

This study was undertaken using content analysis on Berita Harian's news portal and its Instagram to explore the coverage of Covid-19 SOPs through the lens of framing mainly on the use of message styles and interactivity elements. Content analysis is "the systematic assignment of communication content to categorise according to rules, and the analysis of relationships involving those categories using statistical methods" (Riffe et al., 2005). Macnamara (2005) suggested that the method "is used to study a broad range of texts from transcripts of interviews and discussions in clinical and social research to the narrative and the form of films, TV programs and the editorial and advertising content of newspapers and magazines" (p. 1). In this paper, the content analysis provides a systematic analysis of communication materials and the results are presented quantitatively in order to explore the framing portrayal in the selected research samples. The paper presents descriptive and exploratory data specifically on the adoption of the messages style and interactive elements in reporting Covid-19 SOPs.

\subsection{Operationalisation of variables}

The three variables that this study operationalised include standard operating procedures, message styles, and interactive features:

Standard operating procedures (SOPs) of Covid-19 refer to the SOPs as outlined by NSC. It ranges from movement control, restricted activities, activities and protocol, public health protocol, leisure activities' rules to lists of essential services during several movement orders namely Movement Control Order (MCO), Restricted Movement Control Order (RMCO), Conditional Movement Control Order (CMCO), and Recovery Movement Control Order (RMCO). Each order differs based on the level and nature of restrictions.

Message styles are of two types, 1) Narrative and 2) Non-narrative. Narrative style refers to a story-like presentation that is entertaining and informative simultaneously works to appeal to emotions. As for the non-narrative style, messages are presented with factual information and objective arguments.

Interactive features are operationalised using several elements that are available on online platforms. The elements analysed in this study are 1) Links to external sources, 2) 
Hashtags, 3) Questions to solicit feedback, 4) Email address of reporters, 5) Photos, (6) Videos, and (7) Infographics - e.g., maps, posters, statistics.

\subsection{Data collection}

The data selected in this study are news related to SOPs from Berita Harian online newspaper and its Instagram from the day the MCO was effective until the end of 2020. Since the study only focuses on Covid-19 SOPs, all other issues are excluded from the analysis. Stories and live features on Instagram are also excluded as they only lasted for 24 hours. There were 206 online news items and 196 Instagram posts related to Covid19 SOPs gathered in total. The number is manageable and sufficient to ascertain the reporting pattern of Covid-19 SOPs. As the study focuses on the presentation of Covid-19 SOPs through the types of message style and interactive features, the result is not applicable for generalisation. However, since the research is exploratory in nature, the findings can be used to understand how Berita Harian use framing, particularly the message style and interactive elements on the news portal and Instagram.

\subsection{Inter-coder reliability test}

Two coders who are proficient in Malay and English were hired and trained to perform the content analysis. The coders gathered and coded all data based on a code book that was partly adopted from Ngai et al. (2020) and developed for this study. Each coder used a separate code sheet in a Microsoft Excel format. An inter-reliability test was conducted on 30 news items prior to data collection. During the process, both coders and researchers met to discuss and reconcile any disagreements on coded items. The reliability test is vital as a strong reliability result will enhance the quality of the instrument (Gheyle \& Jacobs, 2017). Using Cohen's kappa, the average agreement on the majority of the categories was reported as higher than 0.80 . The result indicated an almost perfect agreement since the acceptable value of Cohen's kappa should be greater than 0.75 in most situations as proposed by Neuendorf (2002) and Banerjee et al. (1999). The reliability test indicated that both coders had almost similar understanding and were able to match the contents coded with the respective coding categories used in the analysis. The reliability for each code is reported in Table 1.

Table 1: The results of an inter-rater reliability test

\begin{tabular}{llll}
\hline $\begin{array}{l}\text { Characteristics } \\
\text { of Posts }\end{array}$ & Sub-Profile & $\begin{array}{l}\text { N=30 } \\
\text { Percentage of } \\
\text { Agreement }\end{array}$ & $\begin{array}{l}\text { Cohen's } \\
\text { Kappa }\end{array}$ \\
\hline Message Styles & Narrative & 96.7 & $.889^{*}$ \\
& Non-narrative & 96.7 & $.870^{*}$ \\
News Displays & Links to external sources & 100 & $1^{*}$ \\
& Use of hashtags & 100 & Constant \\
& Use of questions to solicit feedback & 100 & $1^{*}$ \\
& Social media links & 100 & Constant \\
& Email address of reporters & 100 & $1^{*}$ \\
& Share button & 100 & Constant \\
& Use of videos & 100 & $1^{*}$ \\
& Use of photos & 100 & $1^{*}$ \\
& Use of infographics & 100 & $1^{*}$ \\
& Others & 100 & Constant
\end{tabular}


Total Inter-rater reliability of all

98.95

items

Notes: *Value is significant at the $<.001$ level

\section{Result}

\subsection{The exposure of Covid-19 SOPs news on News Portal and Instagram}

Besides the news portal, Berita Harian consistently maintained its presence on Instagram in covering Covid-19 SOPs. From the content analysis, 208 articles appeared in Berita Harian's news portal and 194 posts on Instagram from March 18, 2020, to December 2020. The frequency indicates that the issue exposure in the news portal is slightly higher than on Instagram. Although social media is used by the media, the news portal remained as the main tool to communicate messages of the SOPs (See Figure 1).

Figure 1: The amount of news coverage on news portal and Instagram

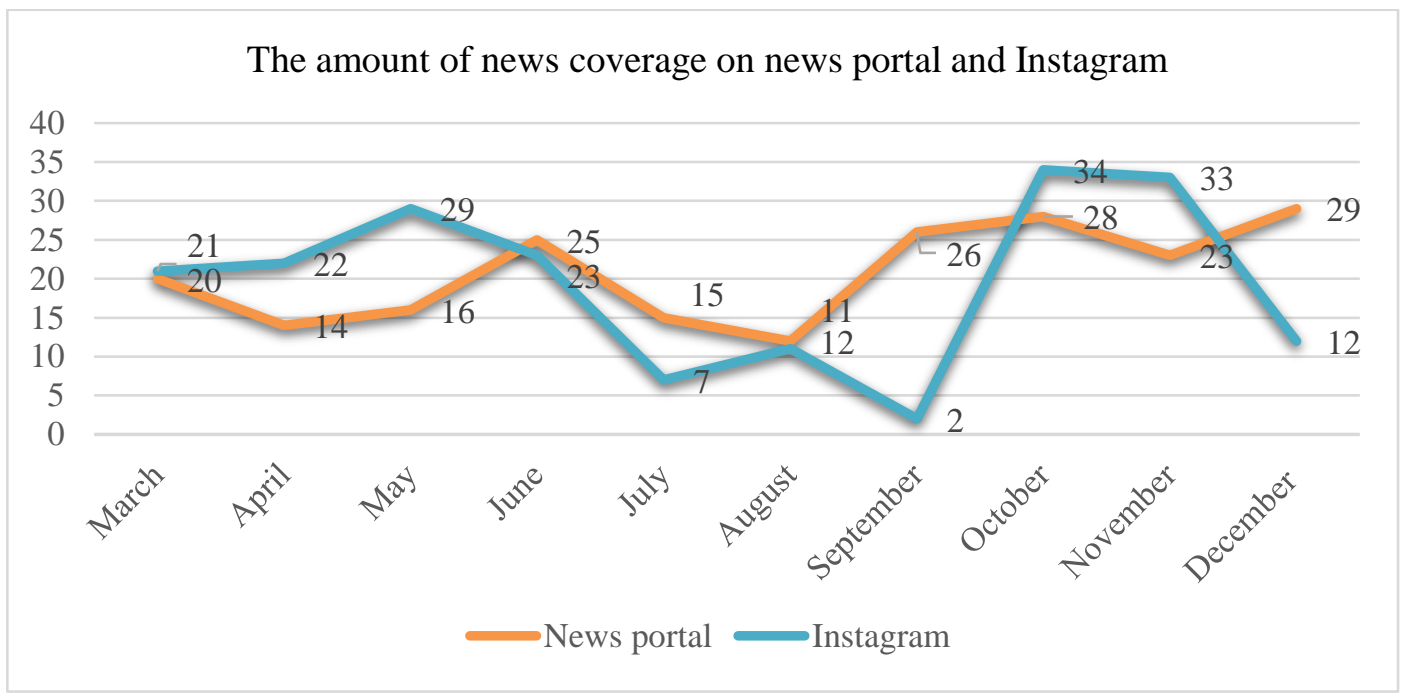

Based on the monthly coverage, there was a variation. The news portal gave high coverage in March and was laid low in the months after. Instagram was consistent in providing high coverage during the first four months after MCO was effective. In September, the coverage of the SOPs was high in the news portal with 26 news as opposed to only two posts on Instagram. Thirty-eight percent of the news portal coverage focused on actions taken against those who violated the SOPs while $15 \%$ was on Kedah as the state which was placed under the Enhanced Movement Control Order (EMCO) on September 11, 2020. Despite the Sabah state election that took place on September 26, 2020, only $7.6 \%$ of news focused on the ongoing election. Meanwhile, the study recorded an increase in coverage in both platforms from October 2020 onwards. In October 2020, for example, the news was mostly related to details of SOPs in the news portal (50\%) and Instagram (64\%). The coverage related to SOPs of activities was anticipated as Selangor, Federal Territory of Kuala Lumpur and Putrajaya were placed under MCO in October 2020. The data recorded that the highest coverage in the news portal was in December 2020 with 29 news as opposed to 12 posts only on Instagram. Despite these variations, the total coverage in both platforms indicates the consistent importance given to the SOPs-related issues. 


\subsection{Message Styles Used to Cover Covid-19 SOPs}

The study also analysed the message styles in the coverage of Covid-19 SOPs in answering RQ2. The results revealed that, in the news portal, 92.3\% of news used nonnarrative presentation and only $7.7 \%$ news reported using narrative. Similarly, the nonnarrative style (95.9\%) was dominant as compared to the narrative style $(12.9 \%)$ in Instagram - (See Table 2).

Table 2: The types of message styles in Berita Harian news portal and Instagram

\begin{tabular}{lllll}
\hline & News portal & & Instagram & \\
& $\mathbf{N}$ & $\mathbf{\%}$ & $\mathbf{N}$ & $\mathbf{\%}$ \\
\hline Narrative & 16 & 7.7 & 25 & 12.9 \\
Non-narrative & 192 & 92.3 & 186 & 95.9 \\
N & 208 & & 194 & \\
\hline
\end{tabular}

\subsection{Interactive Features on Berita Harian News Portal and Instagram}

This part analysed the use of several interactive features in Berita Harian's news portal and Instagram on the coverage of Covid-19 SOPs. The use of interactive features is indispensable in online news presentations. Most studies used several interactive features to report an issue as the functions were made available on both platforms. Among the interactive features analysed were video, photo, infographic, links to external sources, hashtags, questions to solicit feedback, email of reporters and others.

Table 3 showed that Berita Harian is still operating its news portal conservatively as pictures were mostly (83.2\%) used. This is followed by the email address of reporters which is marked at $76.4 \%$ and video at $32.2 \%$. A small number of cases employed links to external sources (5.8\%). The least used features were questions to solicit feedbacks and infographics at $5.3 \%$, respectively and others (1\%). The others were referred to information related to the Sabah state election and CMCO location in Klang as presented in a table form.

Table 3: The use of interactive features on Berita Harian's news portal

\begin{tabular}{lll}
\hline Types of interactive features & $\mathbf{N}$ & $\mathbf{\%}$ \\
\hline Use of videos & 67 & 32.2 \\
Use of photos & 173 & 83.2 \\
Use of infographics & 11 & 5.3 \\
Links to external sources & 12 & 5.8 \\
Use of hashtags & 0 & 0 \\
Use of questions to solicit feedback & 11 & 5.3 \\
Email address of reporters & 159 & 76.4 \\
Others & 2 & 1.0 \\
$\mathrm{~N}$ & 208 & \\
\hline
\end{tabular}

In this study, video, photo, and infographics were considered as elements in visual presentations on Instagram. The results showed more than half of the Covid-19 SOPs posts used videos (56.7\%), followed by infographics (27.8\%). Even though Instagram was popularised through its photo-sharing function, photos were used minimally (15.5\%) (See Table 4). As a visual communication platform, Instagram allows users to upload up to 10 photos or videos in each post. The functionality corresponded with the 
social function of Instagram to target users who prefer more engaging visual information over words. The study also recorded other features on Instagram. It is found that only $17 \%$ of posts used hashtags followed by questions to solicit feedback $(2.6 \%)$ and the least preferred was links to external sources (1\%). While the email to reporters was not coded since the initial observation found that its usage is infrequent on Instagram posts.

Table 4: The use of interactive features on Berita Harian's Instagram

\begin{tabular}{lll}
\hline & Instagram & \\
\hline Types of interactive features & Frequency & $\mathbf{\%}$ \\
\hline Use of videos & 110 & 56.7 \\
Use of photos & 30 & 15.5 \\
Use of infographics & 54 & 27.8 \\
Links to external sources & 2 & 1 \\
Use of hashtags & 33 & 17 \\
Use of questions to solicit feedback & 5 & 2.6 \\
Others & 0 & 0 \\
$\mathrm{~N}$ & 194 & \\
\hline
\end{tabular}

\section{Discussion}

\subsection{The exposure of Covid-19 SOPs news on News Portal and Instagram}

The data inferred that the newness and unusual events related to SOPs of each order gave importance for the issue to be highlighted in both platforms. While low coverage was given, especially in the news portal, as there was no important development on the issue. However, many uncertainties on the dos and don'ts were clarified. The study also suggested that the adoption of Instagram by Berita Harian fit into a format known as 'incidental exposure', that is "exposing more users to news content [...] to attract more social media news consumers and obtain competitive advantage" (Ahmadi \& Wohn, 2018, p. 7). The incidental exposure has facilitated the media to adapt news contents that suit the functionalities of Instagram to attract news users (Vazquez-Herrero et al., 2019). In this usage, Berita Harian's Instagram page could be suggested to contribute to the news distribution and consumption revolution.

\subsection{Message Styles Used to Cover Covid-19 SOPs}

Although the use of both styles is pertinent to offer descriptions of the issues reported, the narrative element is argued to be more impactful to appeal to readers especially using anecdotal and personal information (Ngai et al., 2020; McKinnon \& Orthia, 2017). Since news on SOPs were mostly to raise awareness, distribute knowledge on preventive measures, and teach the public (Colistra, 2012) on the restrictions of each movement order, the aim is to persuade the public to change their behaviour. Hence, using a technique that appeals to emotions is important. The way messages are presented could influence effectiveness (Ngai et al., 2020), while informative and logical texts in the nonnarrative style could provide clarity to information. It is understood that the news portal used more non-narrative presentation as it helped to clarify messages pertaining to SOPs such as procedural information and legal jargon in press statements as proposed in Aristotle's model of rhetoric, logos, a fact-based logical argument (McKinnon \& Orthia, 2017). However, using more narrative presentations, the news can provide more valuebased information to readers. 
Meanwhile, the minimal use of narrative style is predictable based on the features offered in Instagram. Instagram allows not more than 350 characters in each post which is considered lengthy to provide a summary and too short for full information. Instagram is a social media platform that is known for its visual presentation such as pictures and videos than the usual narration. The study indicates that since narrative format could downplay the visual presentation, hence its low adoption. Besides, the visual itself narrates the issue being posted. For these reasons, Berita Harian's Instagram page remained steadfast in accommodating its users who have specific preferences when using the platform. Husemann et al. (2015) proposed that knowledge about recipients is vital to communicate health-related messages effectively. Therefore, by understanding Instagram users' preferences, Berita Harian can tailor the messages pertaining to SOPs accordingly.

\subsection{Interactive Features on Berita Harian News Portal and Instagram}

Berita Harian did not fully utilise the interactive options available on the news portal such as videos, infographics, and links to external sources that might encourage users to further engage with the issues reported. Hashtag remained unpopular although its usage was commonly observed on the reportage of Malaysian election campaigns in some online newspapers. The hashtag was not used even though its utilisation is more likely to link messages of Covid-19 SOPs to other sources (Vazquez-Herrero et al., 2019), hence giving people access to more information than they would obtain traditionally. Email address of reporters was used quite dominantly in the news portal though not in all news. The usage could allow the users and the reporters to engage especially on the topic covered. This supports the interactivity concept as suggested by Stroud et al. (2015) as reporters will be perceived to be more open to receiving feedback and updates from the public. The study suggested that despite the options of interactivity on the news portal, Berita Harian placed great importance on Covid-19 SOPs text-only coverage. While the photo was dominant, it is still considered as a supplementary to text presentation since not all news featured photos. Berita Harian should consider using more visual presentations since space is no longer an issue and colour is not as costly as its print version.

While in Instagram, the use of videos can be argued to accommodate devices (e.g., smartphones) that people use to access information (Vazquez-Herrero et al., 2019). The preference for video could be due to its visual and audio elements that offer richer presentation. While a video is visually attractive, it allows users to skip reading making the text secondary in each post. Technically, unlike other social media platforms such as Facebook and Twitter, visuals on Instagram play a major role to provide information, while the text is used to supplement a post. Visual also functions to influence how people perceive the content (Wojdynski, 2008). This is evident in how Instagram presents stories on users' feeds that automatically plays a video and shows photos, while the accompanying texts are shortened. The majority of the videos analysed used narration from reporters while only a few used background music without narrations. The study also found that the videos were shared contents as indicated through an animated watermark BH TV/NST TV/Metro TV on the upper left side. Since Berita Harian, New Straits Times, and Harian Metro are under Media Prima Berhad, a media conglomerate, the sharing of content is common. 
The results further showed that infographic was commonly used to compile facts pertaining to Covid-19 SOPs such as regulations, frequently asked questions, or announcements, that are usually lengthy, into an easy-to-read format. For example, on March 17, 2020, an infographic containing illustrations and details of regulations during MCO in areas of education, social activities, religious activities, and many others was shared on Berita Harian's Instagram page. The infographic facilitates comprehension and is also distinguishable. In some other instances, the infographic was also used as a one-line reminder with a graphic illustration to follow certain rules. For example, as shared on Berita Harian's Instagram page on August 3, 2020, and April 9, the post featured an illustration of a mask and police and a lawbreaker, respectively. It is important to note, the file format of all infographics used on Instagram is compatible with a screen resolution of smartphones, in which enlarging them would not affect information clarity. Infographics are crucial to make Covid-19 SOPs posts more engaging and easier to follow. Its usage corresponded with the features offered by Instagram.

Despite its popularity, the hashtag was surprisingly not dominant in most Covid-19 SOPs posts. A hashtag can increase the visibility of Instagram posts as it allows the ease to search certain topics. As proposed by Threlfall (2009), hashtag helps in building resources when being used by many. Even though users can use up to 30 hashtags on a normal post, this study found limited hashtags being used and they were mainly general such as \#COVID19, \#Infografik, and \#PKPB. By using the main hashtags, it is suggested that Berita Harian is being tactful to keep the focus small particularly on Covid-19 and movement orders only.

\section{Implications}

The use of online news portal in disseminating health issues have long been practised by media organisations and embraced by the public even before the emergence of Covid19. As digital media keeps evolving, likewise media as the information providers. The presence of news organisations on social media is vital to keep the public informed of the current Covid-19 issues. This could be suggested as a means to combat the spread of falsehood on social media by certain individuals such as that of anti-vaxxers on Facebook as examined by Ghazali et al. (2021).

From a general perspective, the current media landscape lack standardised formatting of information consumption and production as the technology keeps evolving affecting almost all aspects of communication. For this reason, this study suggests that Berita Harian should consider using more interactive elements such as photos, infographics, and videos on its news portal due to the unlimited space that is less costly than its print version. Considering contemporary health realities, it is further imperative that media organisations use all social media platforms to shape, construct, and alter the minds of the public into realising Covid-19 as one of the main health threats. Overall, the results of this research can be extended to the discussion of framing by emphasising the adoption of interactive elements as the aspects of coverage as proposed by Entman (1993).

\section{Conclusion}

In conclusion, Berita Harian maintains an equal presentation on social media through the analysis of its Instagram account besides its news portal. It can be deduced from the results that while text dominated Berita Harian's news portal, videos played a major role 
in the coverage of Covid-19 SOPs on Instagram. The study found that the elements of interactivity help to enhance the way news is portrayed in engaging social media users. Unlike the traditional way that requires users to find information on the news portal, Instagram functions by exposing users to stories on their feeds, and users have to select which stories to engage further. Just like other platforms, Instagram is an important medium for Berita Harian to reach out to more incidental users. Therefore, this study calls for more research into how the interactive elements of the news portrayal evolve and affect the audience into perceiving the Covid-19 coverage and other issues of importance.

\section{Acknowledgement}

The researchers wish to thank all the research assistants involved in the data collection.

\section{Funding}

This research paper is funded by the Malaysian Ministry of Higher Learning's Fundamental Research Grants Scheme titled 'Formulating an Effective Guideline on Online Resources Pertaining to the Misunderstanding of Vaccination and Its Importance' (Project ID: FRGS19-107-0716).

\section{Conflict of Interests}

The authors declare no conflict of interest in this study.

\section{References}

Ahmadi, M. \& Wohn, D.Y. (2018). 'The antecedents of incidental news exposure on social media'. Social Media \& $\quad$ Society, 4(2). https://doi.org/10.1177\%2F2056305118772827

Badawy, A., Gharawi, M.A., Bidin, A., \& Khamis, M. (2020). 'Role of ministerial media arms during COVID-19 in Malaysia'. Al-Hikmah International Journal of Islamic $\begin{array}{llll}\text { Studies } \quad \text { Human } & \text { 3(4), }\end{array}$ https://doi.org/10.46722/hikmah.v3i4.79

Banerjee, M., Capozzoli, M., McSweeney, L., \& Sinha, D. (1999). 'Beyond kappa: A review of interrater agreement measures'. Canadian Journal of Statistics, 27(1), 3-23. https://doi.org/10.2307/3315487

Barnard, S.R. (2016). 'Tweet or be sacked: Twitter and the new elements of journalistic practice'. Journalism, 17(2),

190-270. https://doi.org/10.1177\%2F1464884914553079

Bowd, K. (2016). 'Social media and news media: Building new publics or fragmenting audiences?'. In Griffiths, M., and Barbour, K. (Eds.), Making publics, making places (pp.129-144). South Australia: University of Adelaide Press

Bryant, J., \& Miron, D. (2004). 'Theory and research in mass communication'. Journal of communication,54(4),662-704.https://psycnet.apa.org/doi/10.1111/j.14602466.2004.tb02650.x

Colistra, R. (2012). 'Shaping and cutting the media agenda: television reporters' perceptions of agenda-and frame-building and agenda-cutting 
influences'.Journalism \& Communication Monographs, 14(2), $\quad$ 85-146. https://doi.org/10.1177\%2F1522637912444106

Entman, R.M. (1993). 'Framing: Toward clarification of a fractured paradigm', Journal of communication, 43(4), 51-58

Ghazali, W.N.W.M., Mohamed, S., Nasir, N.S.M., \& Yusoh, M.H. (2020). The coverage of vaccination in the Malay newspapers: an exploratory study. Asian Journal of Applied Communication, 9(1), 351-366.

Ghazali, W.N.W.M., Idris, H., Mohamed, S., \& Nasir, N.S.M. (2021). Typology of vaccine refusals on Facebook in Malaysia. Search Journal of Media and Communication Research, 13(3), 55-70.

Gheyle, N., \& Jacobs, T. (2017). Content Analysis: a short overview. Internal research note. Centre forEUStudies.https://www.researchgate.net/profile/NielsGheyle/publication/321977528_Content_Analysis_a_short_overview/links/5a3bee 680f7e9b10e23bb2f9/Content-Analysis-a-short-overview.pdf

Goffman, E. (1974). Frame analysis: An essay on the organization of experience. Harvard University Press

Husemann, S., \& Fischer, F. (2015). 'Content analysis of press coverage during the H1N1 influenza pandemic in Germany 2009-2010'. BMC Public Health, 15(1), 1-9. https://doi.org/10.1186/s12889-015-1742-1

Jamal, M., \& Ganapathy, M. (2021). 'Framing the Actors through Thematic Structures: The Case of the Malaysian Orang Asli'. Academic Journal of Interdisciplinary Studies, 10(3), 249-258. https://doi.org/10.36941/ajis-2021-0055

Macnamara, J.R. (2005). 'Media content analysis: Its uses, benefits and best practice methodology'. Asia Pacific Public Relations Journal, 6(1), 1-34. https://opus.lib.uts.edu.au/bitstream/10453/10102/1/2007002122.pdf

Machmud, M., Irawan, B., Karinda, K., Susilo, J., Salahudin. (2021). 'Analysis of the Intensity of Communication and Coordination of Government Officials on Twitter Social Media during the Covid-19 Handling in Indonesia'. Academic Journal of Interdisciplinary Studies,10(3),319-334. http://www.richtmann.org/journal/index.php/ajis/article/view/12473/12073

Matthes, J. (2009). 'What's in a frame? A content analysis of media framing studies in the world's leading communication journals, 1990-2005'. Journalism \& Mass Communication Quarterly, 86(2),

349-367. https://doi.org/10.1177\%2F107769900908600206

McKinnon, M., \& Orthia, L. (2017). 'Vaccination communication strategies: What have we learned, and lost, in 200 years?'. Journal of Science Communication, 16(3), A08. https://doi.org/10.22323/2.16030208

Neuendorf, K.A. (2002). Defining content analysis. Content analysis guidebook. Thousand Oaks, CA: Sage

Ngai, C.S.B., Singh, R.G., Lu, W., \& Koon, A.C. (2020). 'Grappling with the COVID-19 health crisis: Content analysis of communication strategies and their effects on public engagement on social media'. Journal of medical Internet research, 22(8), e21360. https://doi.org/10.2196/21360

Nurhayati-Wolff, H. (2020). Malaysia: Number of Facebook users 2017-2025. Statista. https://www.statista.com/statistics/490484/number-of-malaysia-facebookusers/

Pavlik, J. (2000). 'The impact of technology on journalism'. Journalism studies, 1(2), 229237. https://doi.org/10.1080/14616700050 028226

Rich, C. (2014). Writing and reporting news: A coaching method. 8th edn. Pacific Grove, CA: Wadsworth Publishing 
Riffe, D., Lacy, S., \& Fico, F. (2005). Analyzing media messages: Using quantitative content analysis in research. $2^{\text {nd }}$ edn. London: Routledge

Stroud, N.J., Scacco, J.M., \& Curry, A.L. (2016). 'The presence and use of interactive features on news websites'.Digital Journalism, 4(3), 339-358. https://doi.org/10.1080/21670811.2015.1042982

Tahir, H. M., Padil, N., Rashid, M. S. A., 'Baharom, S. N., \& Kamarudin, D. (2020). 'Visual Communication As A Medium Sending Standard Operating Procedure (Sop) Message To Public During Pandemic Covid-19', Proceedings Of The International Conference Of Innovation In Media And Visual Design (IMDES 2020) (Pp. 17-179). Atlantis Press

Threlfall, C. (2009). The advantages and disadvantages of using Twitter hashtags. SiteProNews. https://www.sitepronews.com/2009/12/14/the-advantages-anddisadvantages-of-using-twitter-hashtags/

Usher, N. (2014). Making news at The New York Times. United States: University of Michigan Press

Vázquez-Herrero, J., Direito-Rebollal, S., \& López-García, X. (2019). 'Ephemeral journalism: News distribution through Instagram stories', Social Media+ Society, 5(4), 2056305119888657. https://doi.org/10.1177\%2F2056305119888657

Wojdynski, B. W. (2008). Multimedia framing in US newspapers' online coverage of the Iraq War [Unpublished thesis]. University of North Carolina

Zulkafli, N.A., Omar, B., \& Hashim, N.H. (2014). 'Selective exposure to Berita Harian Online and Utusan Malaysia Online: The roles of surveillance motivation, website usability and website attractiveness', SEARCH: The Journal of the South East Asia Research Centre for Communication and Humanities, 6(2), 1-21. Doi: 10.7603/s40931-014-0002-7 